\title{
Feasibility Testing of Delayed Scintillator Screens for Indirect Digital Neutron Radiography of Irradiated Nuclear Fuel
}

William C Chuirazzi, Aaron E Craft, Nicholas M Boulton, Glen C Papaioannou, Andrew T Smolinski, Kyrone Riley, Amanda Renee Smolinski

November 2019

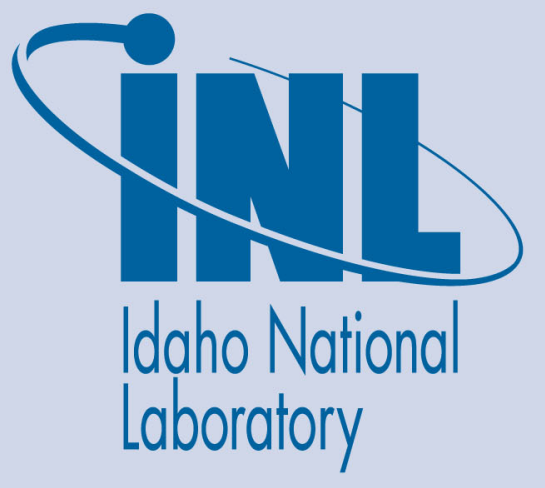

The INL is a U.S. Department of Energy National Laboratory operated by Battelle Energy Alliance 


\section{Feasibility Testing of Delayed Scintillator Screens for Indirect Digital Neutron Radiography of Irradiated Nuclear Fuel}

William C Chuirazzi, Aaron E Craft, Nicholas M Boulton, Glen C Papaioannou, Andrew T Smolinski, Kyrone Riley, Amanda Renee Smolinski

November 2019

Idaho National Laboratory Idaho Falls, Idaho 83415

http://www.inl.gov

Prepared for the U.S. Department of Energy Office of Nuclear Energy Under DOE Idaho Operations Office

Contract DE-AC07-05ID14517 


\section{Delayed Scintillator Screens for Indirect Digital Neutron Radiography of Irradiated Nuclear Fuel}

2019 American Nuclear Society Winter Meeting

Washington, D.C.

November 17-21, 2019

William Chuirazzia ${ }^{a}$, Aaron Crafta ${ }^{a}$, Glen Papaioannou ${ }^{a}$, Amanda Smolinskic, Kyrone Rileya, Andrew Smolinskia and Mike Ruddella

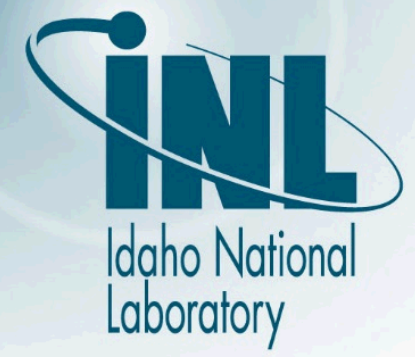
a Idaho National Laboratory
b The Ohio State University
c Idaho State University 


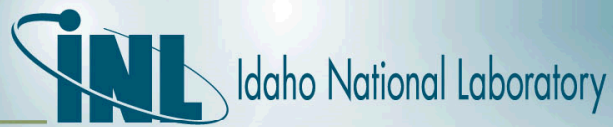

\section{Introduction to Neutron Radiography}

- Neutrons attenuated through

Beer Lampert Law absorption or scattering.

- Neutrons interact with the

$$
I=I_{0} e^{-\mu x}
$$
nucleus.

- X-rays interact with electron shell, so high-Z materials strongly attenuate $\mathrm{X}$-rays.

- Low-Z elements or strong absorbers give high contrast for neutrons.

- Can penetrate high-Z materials.

- Can give isotopic information.

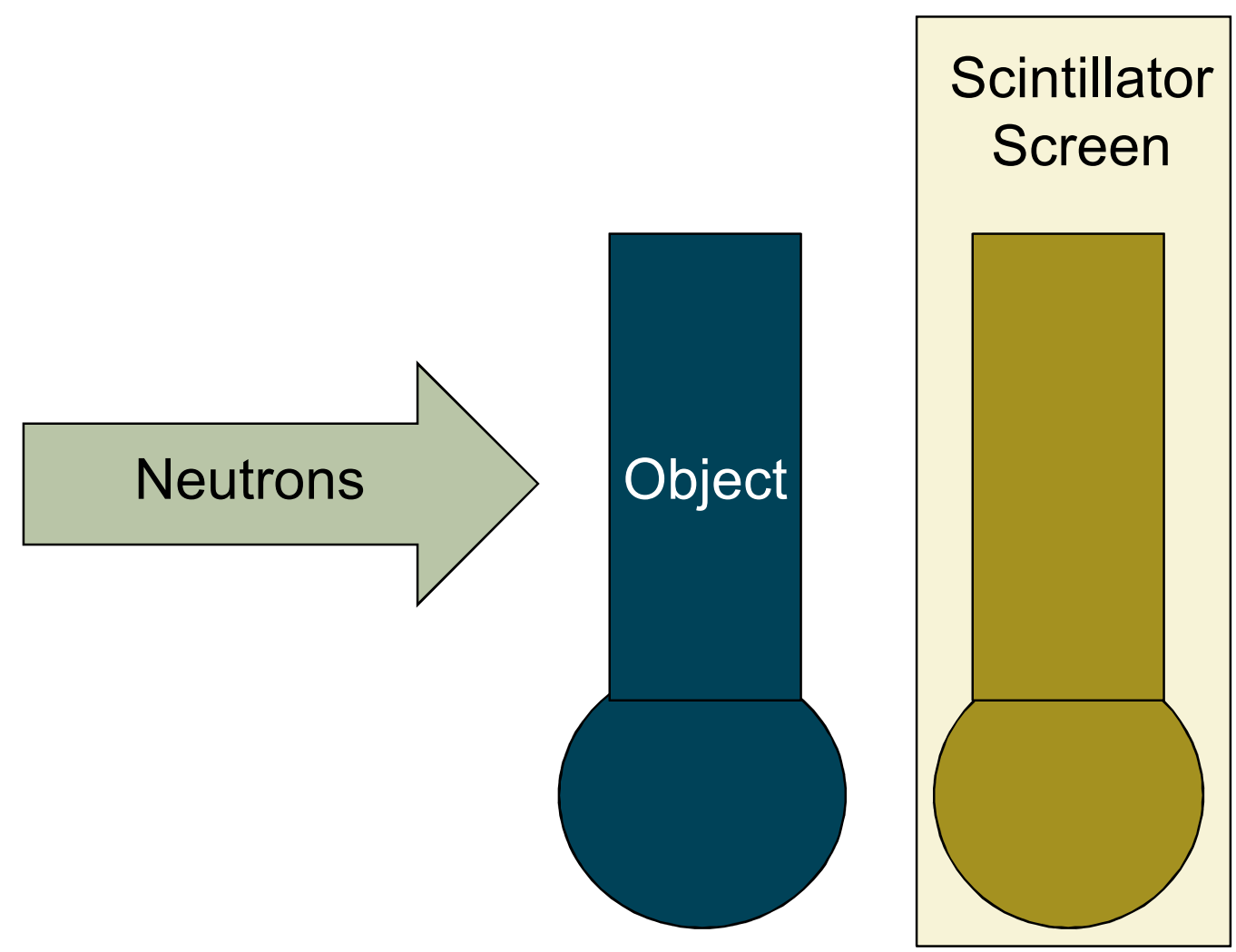




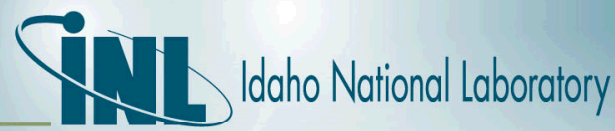

\section{Neutron Radiography}

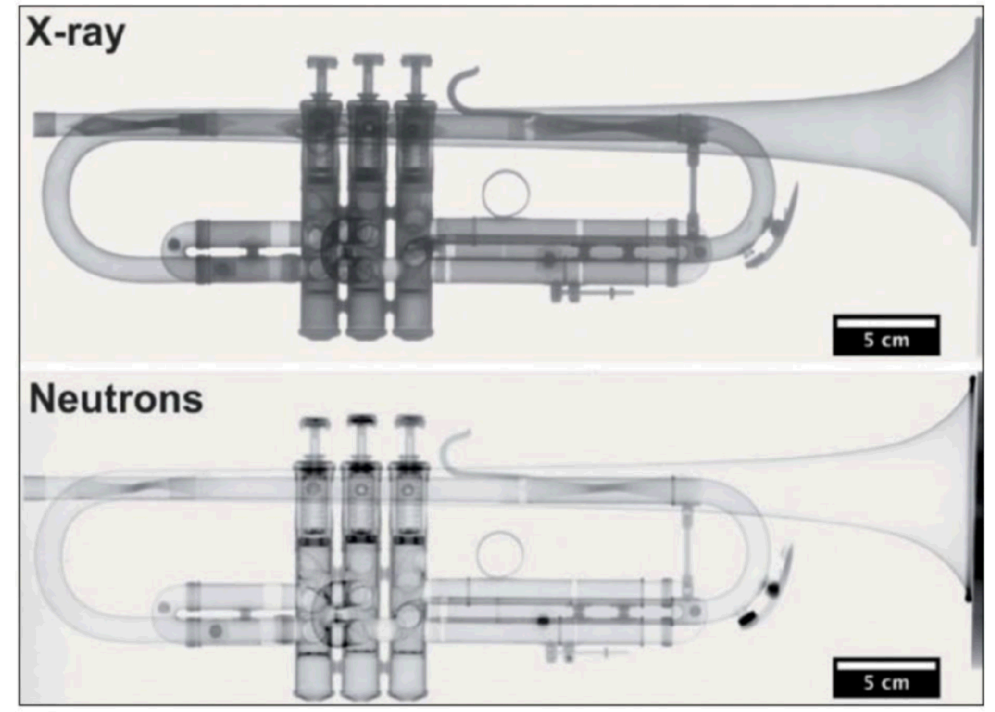

Mannes, David, et al. "X-ray and neutron imaging as complementary non-destructive methods for investigations of historical brasswind instruments." Diagnostic and Imaging on Musical Instruments: Selected proceedings of the 1st and 2nd International Workshop, 2010-2011 Ravenna, Italy. Nardini Editore, 2017

X-ray and neutron images of a trumpet.
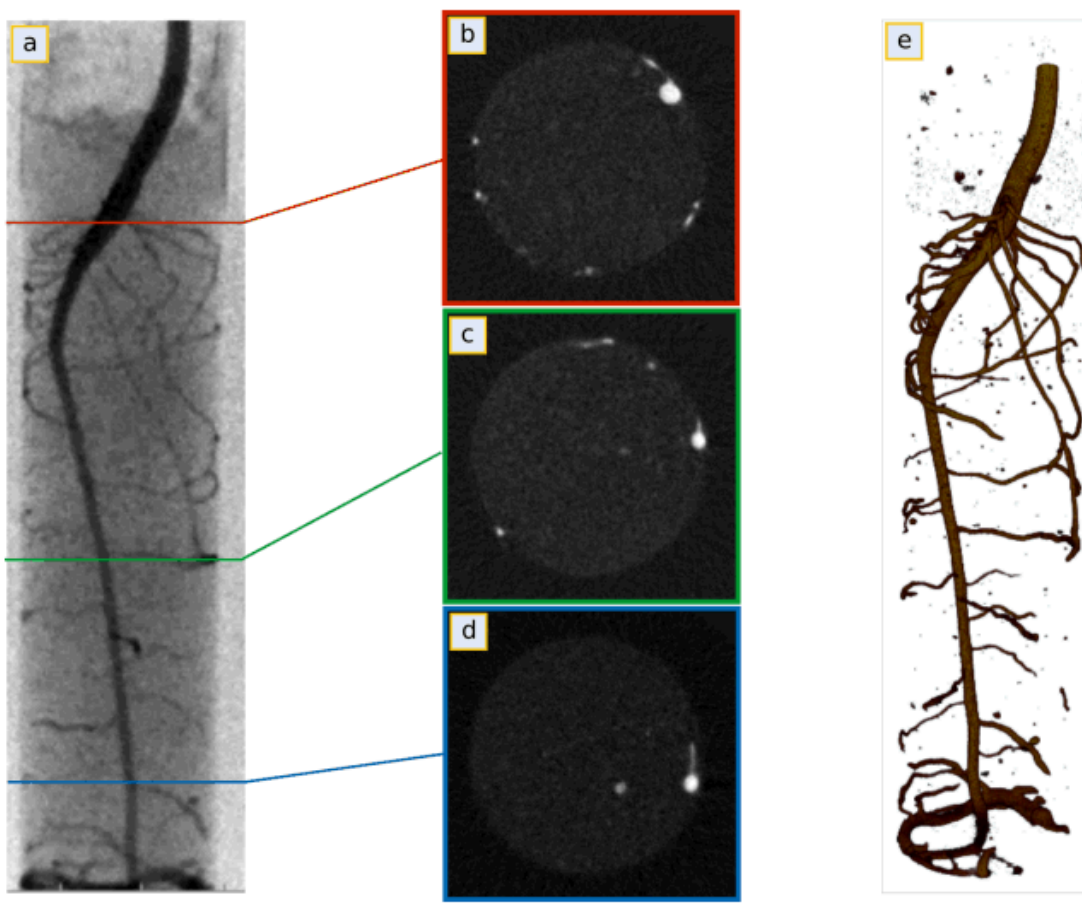

Kaestner, Anders P., et al. "Recent developments in neutron imaging with applications for porous media research." Solid Earth 7.5 (2016): 1281-1292.

(a) Neutron radiograph of a 2-week old lupine in a cylindrical container of sandy soil, $27 \mathrm{~mm}$ in diameter. (b,c,d) Horizontal slices of the reconstructed data at different depths indicated by the colored lines in the radiography. (e) 3D rendering of the root system reconstructed with 181 projections 


\section{Film Radiography (Indirect Method)}

1. Object is placed in the neutron beam and a converter foil is activated in the pattern of the neutrons passing through the object.
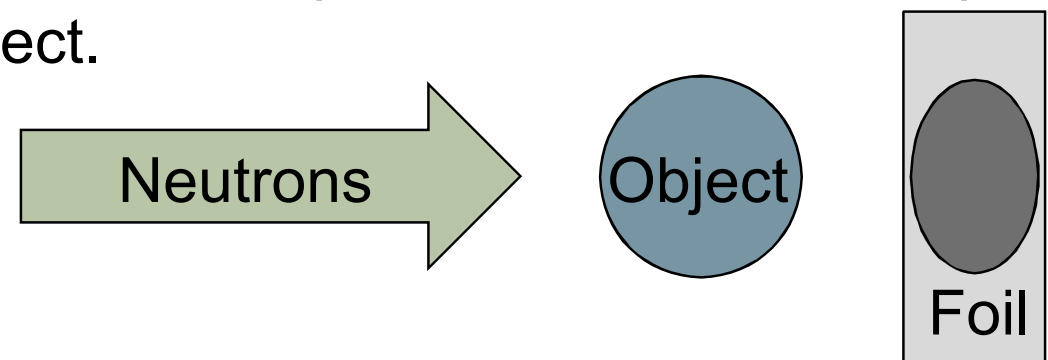

2. The activated foil is placed next to film and the decay radiation exposes the film.

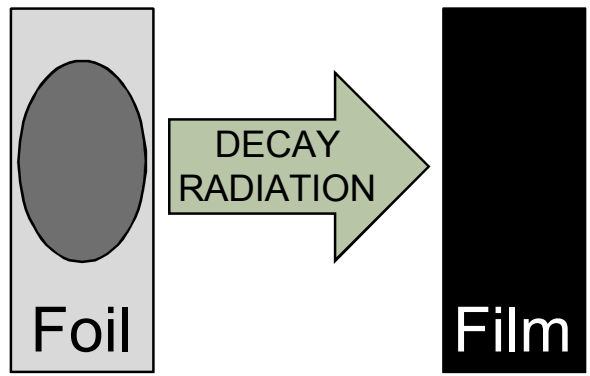

3. The film is processed, producing a neutron radiograph.
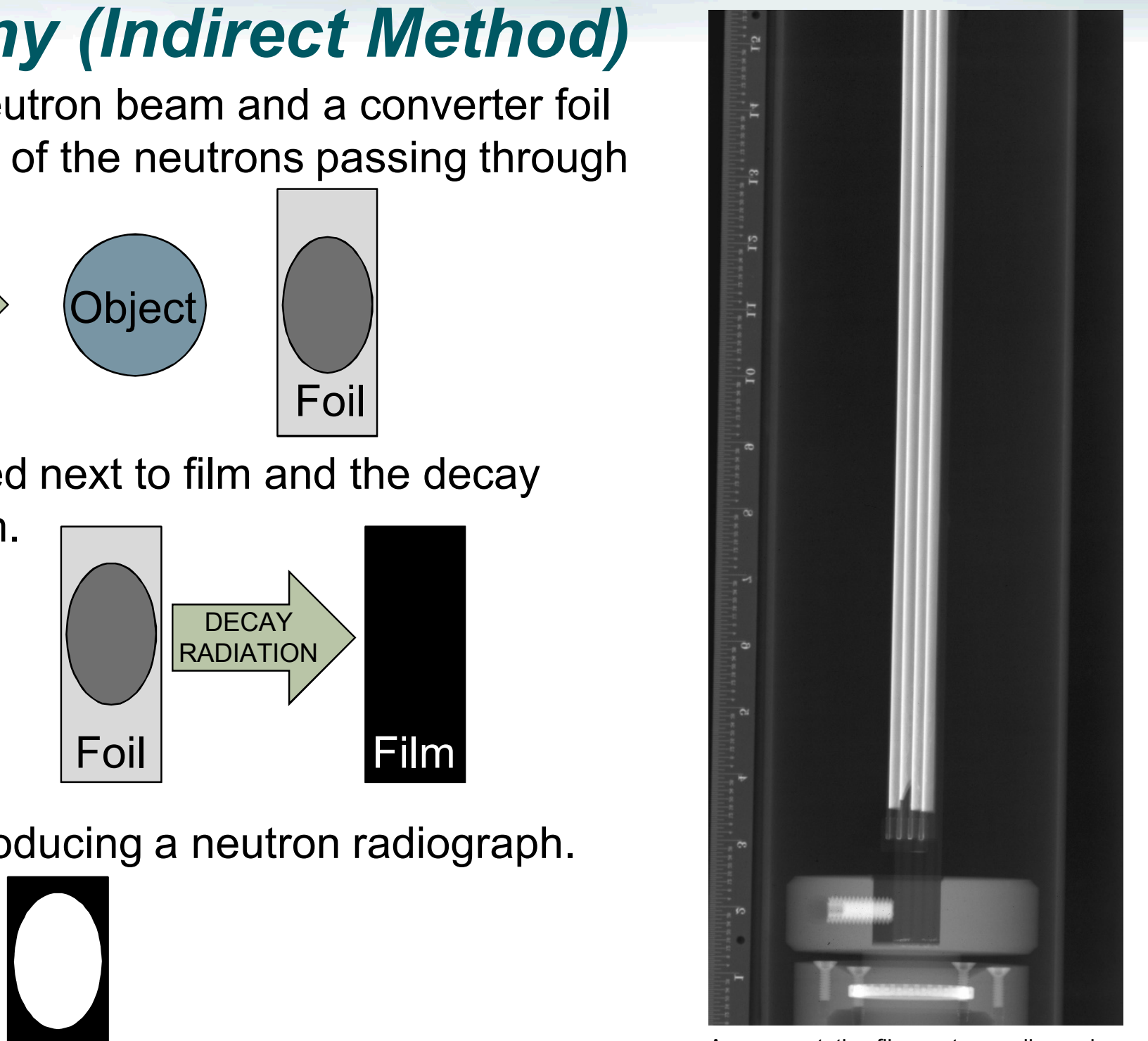

Film

A representative film neutron radiograph of curved nuclear fuel plates taken at INL's NRAD reactor. 


\section{Fid}

\section{Digital Neutron Radiography (Direct Method)}

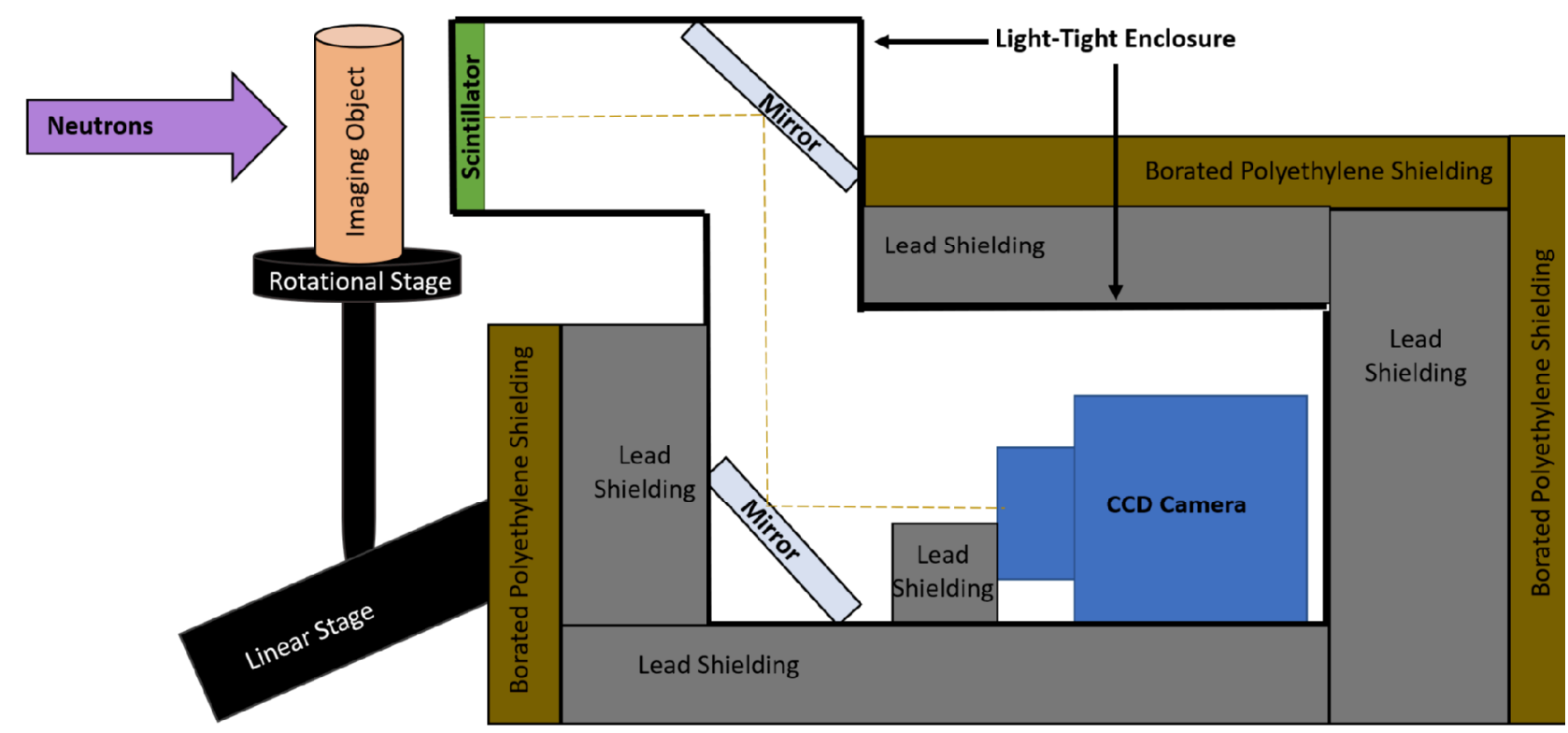

- The object attenuates neutrons, and neutrons passing through the object are absorbed by a scintillator screen.

- Scintillation screen absorbs neutrons and emits photons (visible light).

- A digital camera records photons and renders a digital image.

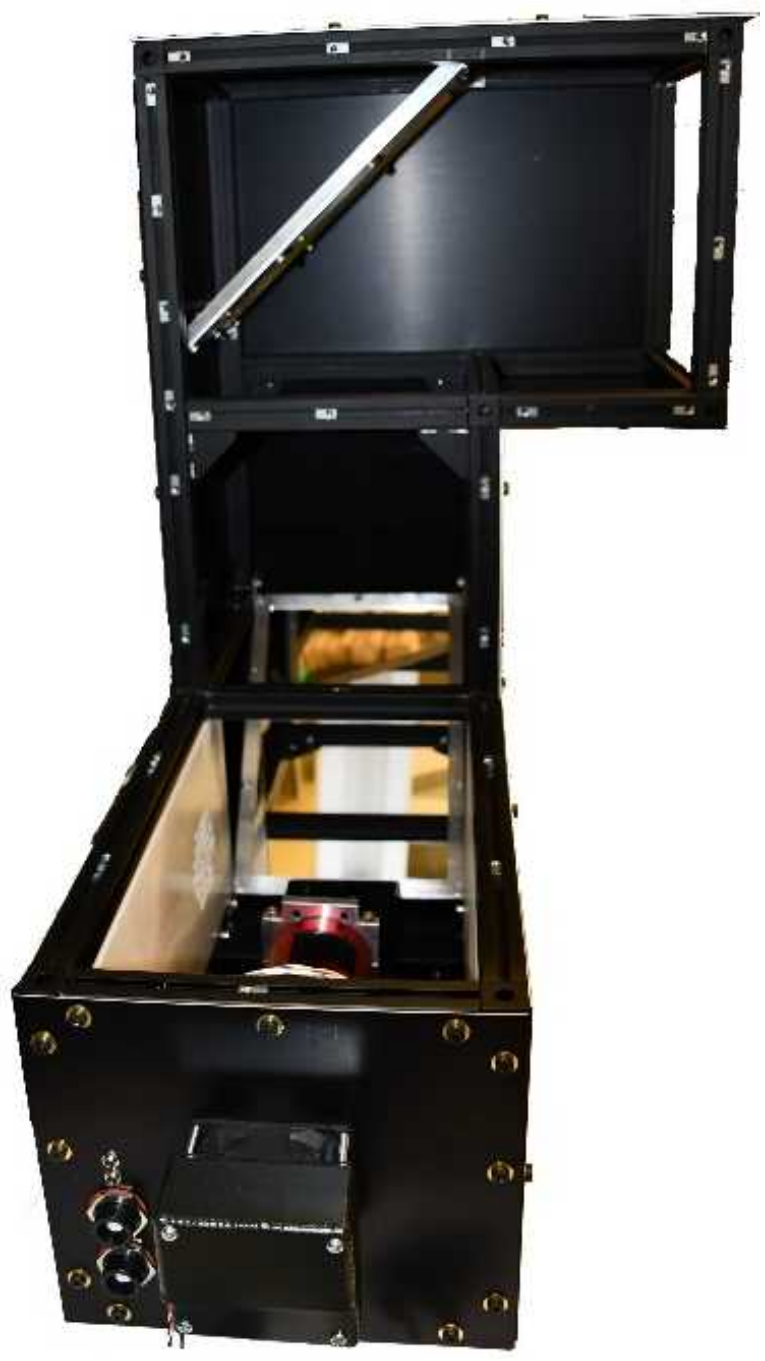




\section{Indirect vs. Direct Methods}

\section{Indirect Neutron Radiography}

- Process is completely gamma insensitive.

- No electronics to be damaged by the radiation field.

- Maintains high resolution with large field of view.

\section{Direct Neutron Radiography}

- Quicker acquisition time.

- Less labor intensive.

- Allows for automatic acquisition of many images for neutron tomography.

- Resolution depends in part on the size of camera's pixel array and field of view. 


\section{Fid}

\section{NRAD Reactor}

- Designed specifically for NR for PIE of fuel.

- The NRAD reactor beneath the HFEF hot cell.

- $250 \mathrm{~kW}$ TRIGA.

- Two neutron beams.

- Access to specimens in the hot cell.

- A unique and valuable facility.

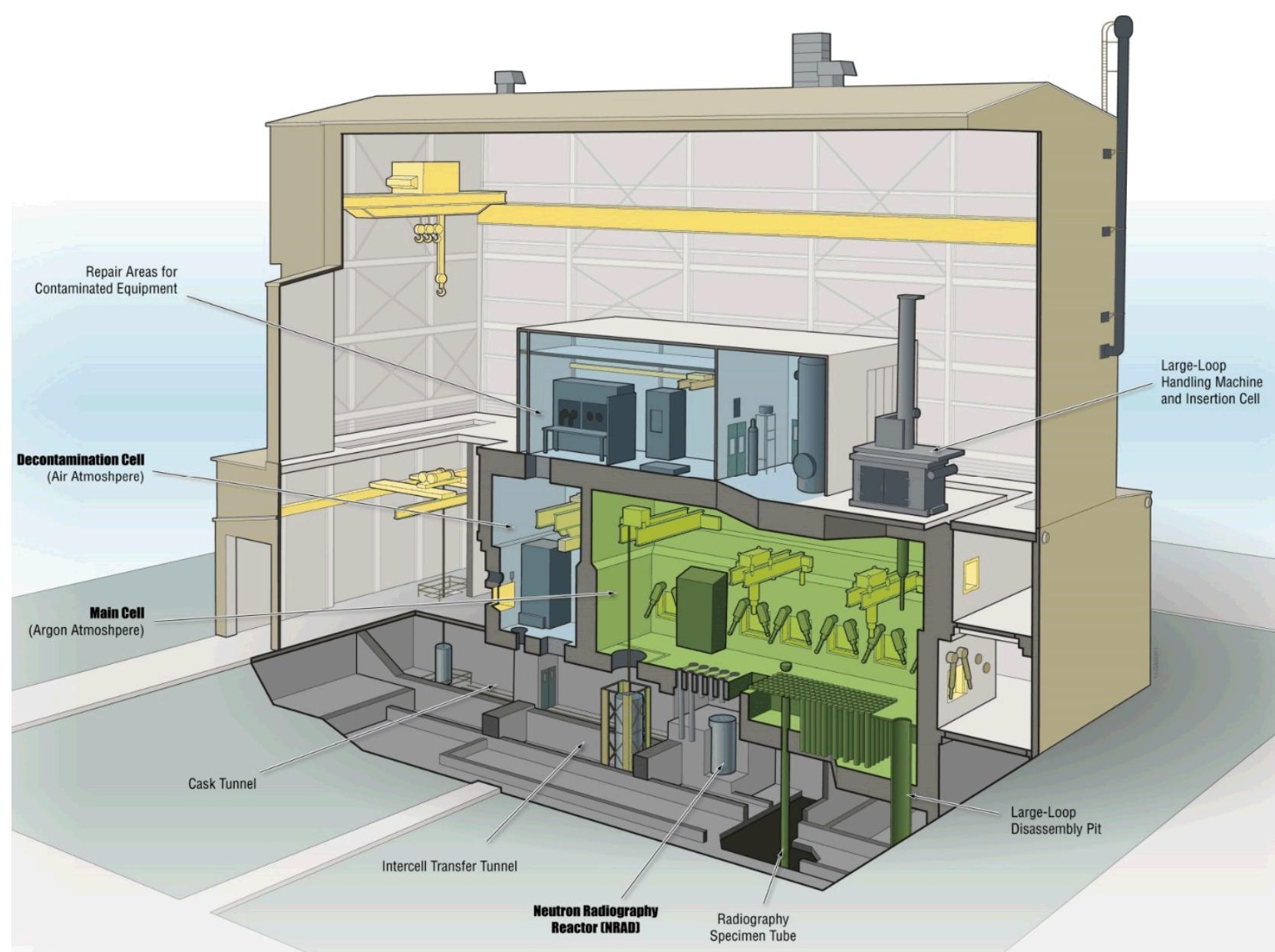




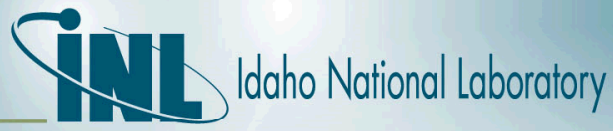

\section{East Radiography Station (ERS)}

- The ERS sits directly beneath the main hot cell.

- A foil cassette is remotely moved behind the elevator for exposure to the beam, then remotely removed for further processing.

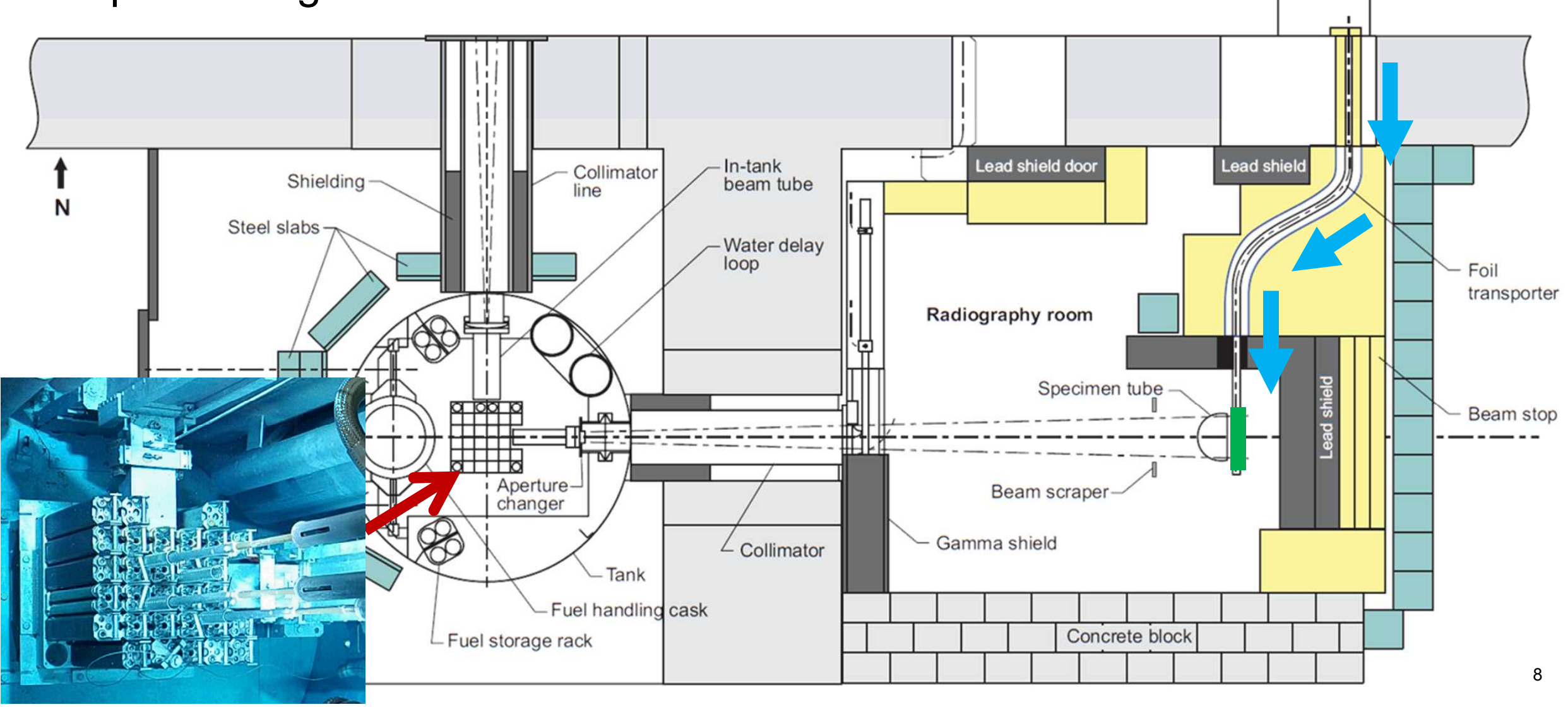




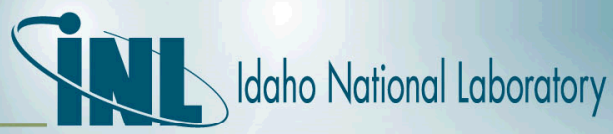

\section{East Radiography Station (ERS)}

- Category-I radiography facility according to ASTM standards.

- Field of view:

$17.8 \mathrm{~cm} \times 43.2 \mathrm{~cm}$ (7"×17").

- Neutron flux: $9.6 \times 10^{6} \mathrm{n} / \mathrm{cm}^{2}-\mathrm{s}$. ${ }^{* * *}$

- L/D ratio: 50, 125, 300

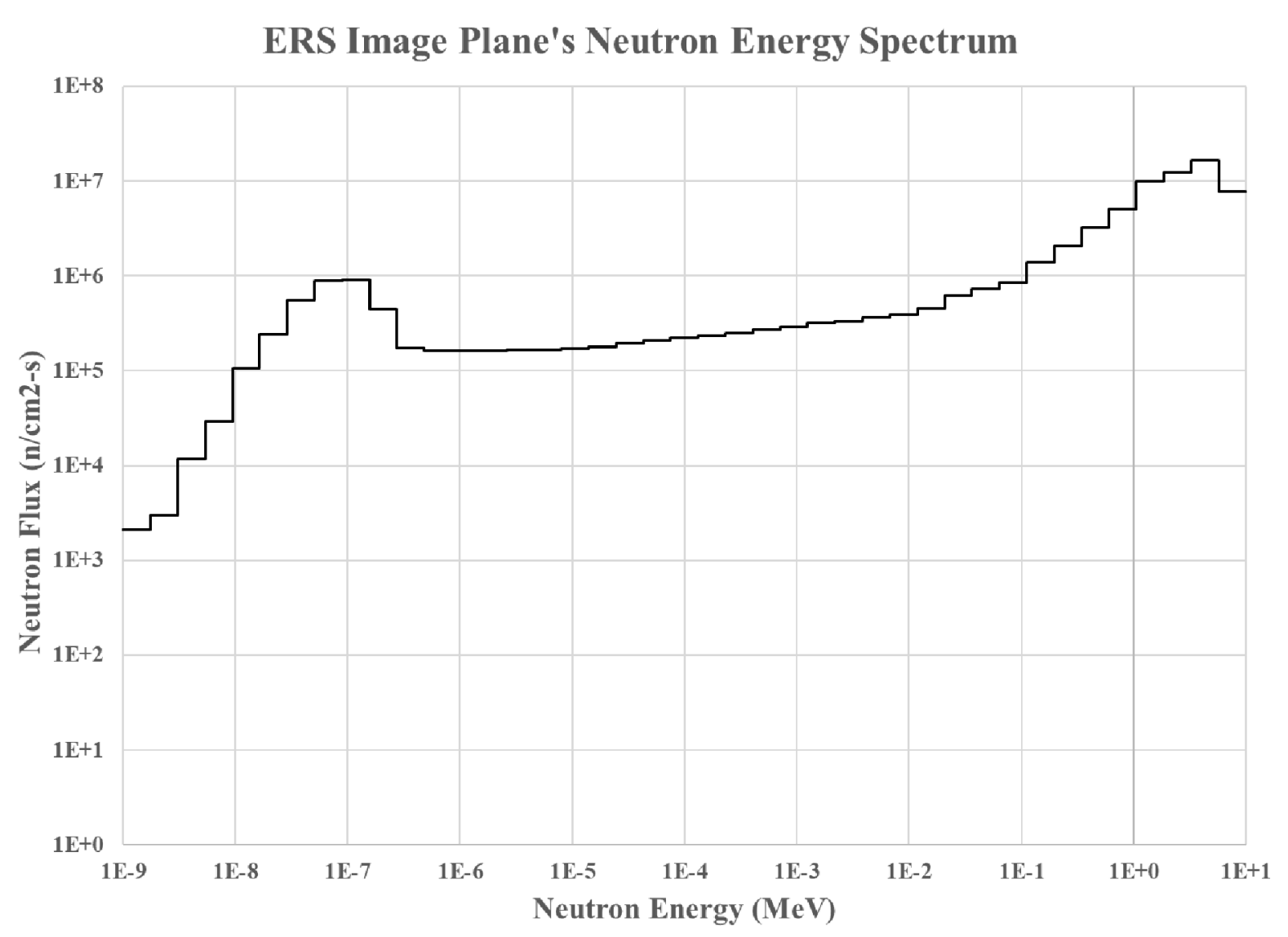

\footnotetext{
${ }^{* * *}$ Equivalent thermal flux measured with gold foil activation. Actual neutron flux is $\sim 3.8 \times 10^{7} \mathrm{n} / \mathrm{cm}^{2} \mathrm{~s}$.
} 


\section{Can we image radioactive fuel with scintillators?}

\section{Challenges:}

- Radiation emitted from irradiated fuel:

- Damages electrical equipment.

- Interacts with the scintillator screen and degrades image quality.

\section{Solution:}

- Combine digital imaging with indirect neutron radiography techniques.

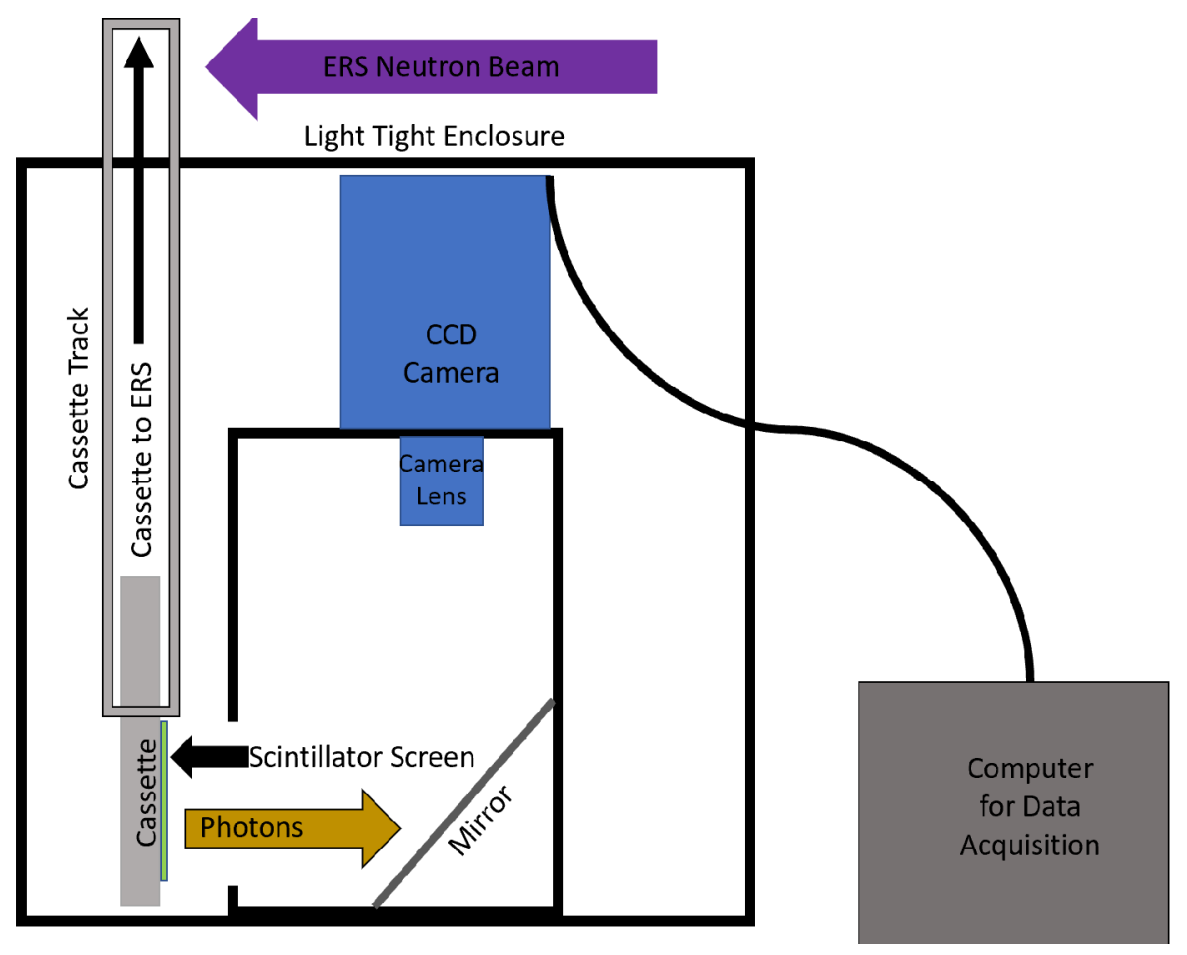

Schematic of Indirect Digital Neutron Radiography 


\section{Neutron Scintillator Screen Requirements}

- Converter:

- Half life must be long enough to store an image during transport.

- Half life must be short enough to produce an image in a reasonable amount of time.

- Scintillator:

- Desire high light output.

- Does not retain a gamma image from afterglow.

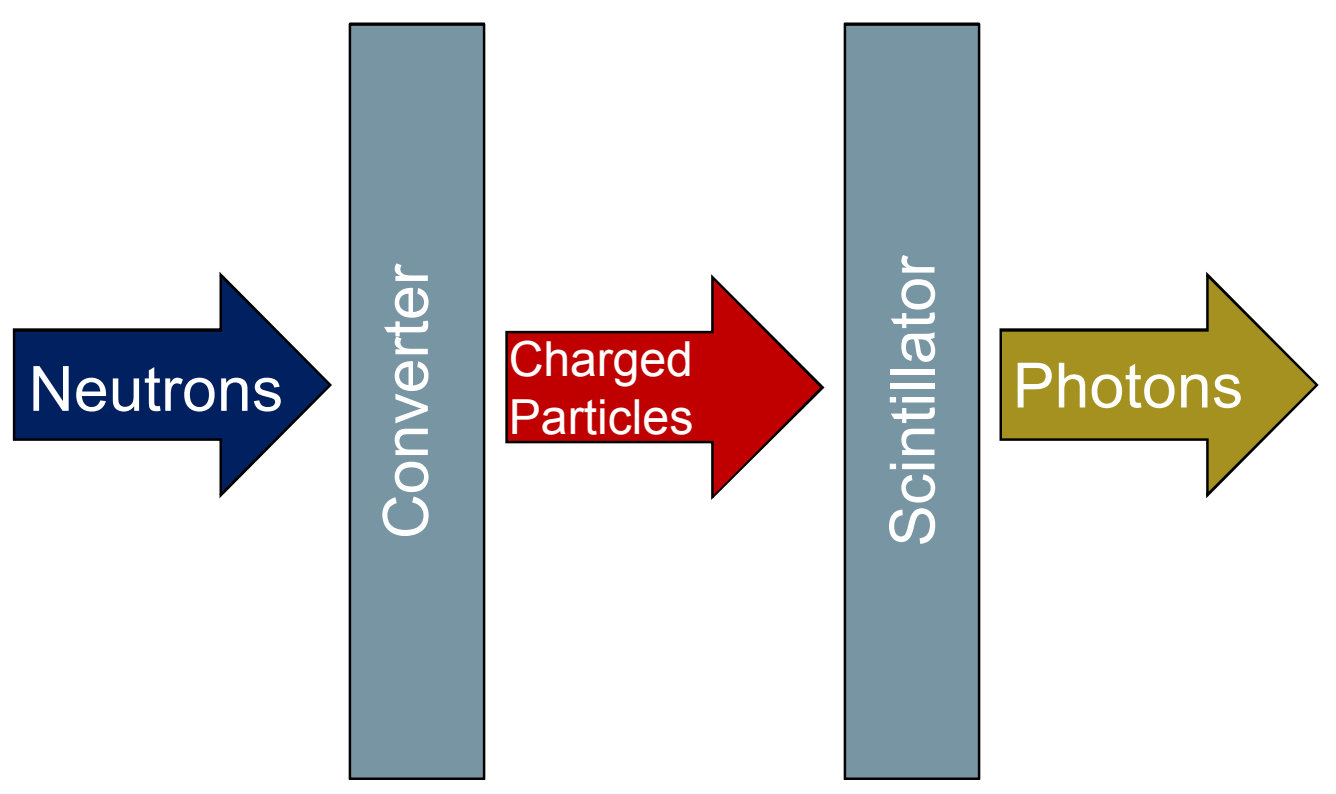

Schematic diagram describing how scintillators convert neutrons to visible-light photons. 


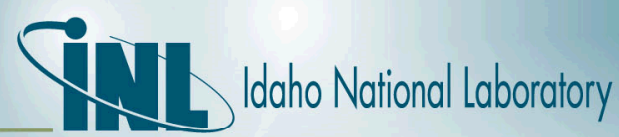

\section{Dysprosium Scintillator Screens}

- Dysprosium foil acts as a neutron converter, releasing $\beta$ - particles and gamma rays.

- ZnS coating releases photons upon interacting with the decay radiation.

$$
\begin{aligned}
& { }_{66}^{164} D y+n \stackrel{\sigma_{a} \approx 1700 b}{\longrightarrow}{ }_{66}^{165} D y \stackrel{t_{1 / 2}=2.33 h}{\longrightarrow} \beta^{-}+{ }_{67}^{165} \mathrm{Ho} \\
& \underset{66}{164} \mathrm{Dy}+n \stackrel{\sigma_{a} \approx 1000 b}{\longrightarrow}{ }_{66}^{165 m} \mathrm{Dy} \stackrel{t_{1 / 2}=1.26 \mathrm{~m}}{\longrightarrow} I T_{\gamma}+{ }_{66}^{165} \mathrm{Dy}
\end{aligned}
$$

- Half life of 1.26 minutes is useful for digital neutron radiography. 


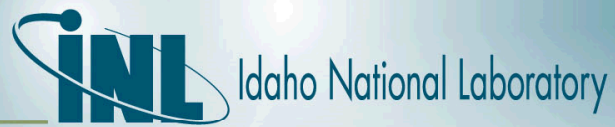

\section{Initial Screen Testing at PSI}

- A collaboration between INL and PaulScherrer Institute (PSI).

- Measurements taken at PSI's NEUTRA thermal beamline.

\section{- A set of 23 screens} tested for light output as a function of time.

- Neutron flux:

$9.8 \times 10^{6} \frac{1}{\mathrm{~cm}^{2} * S * m A}$.

$L / D=350$.

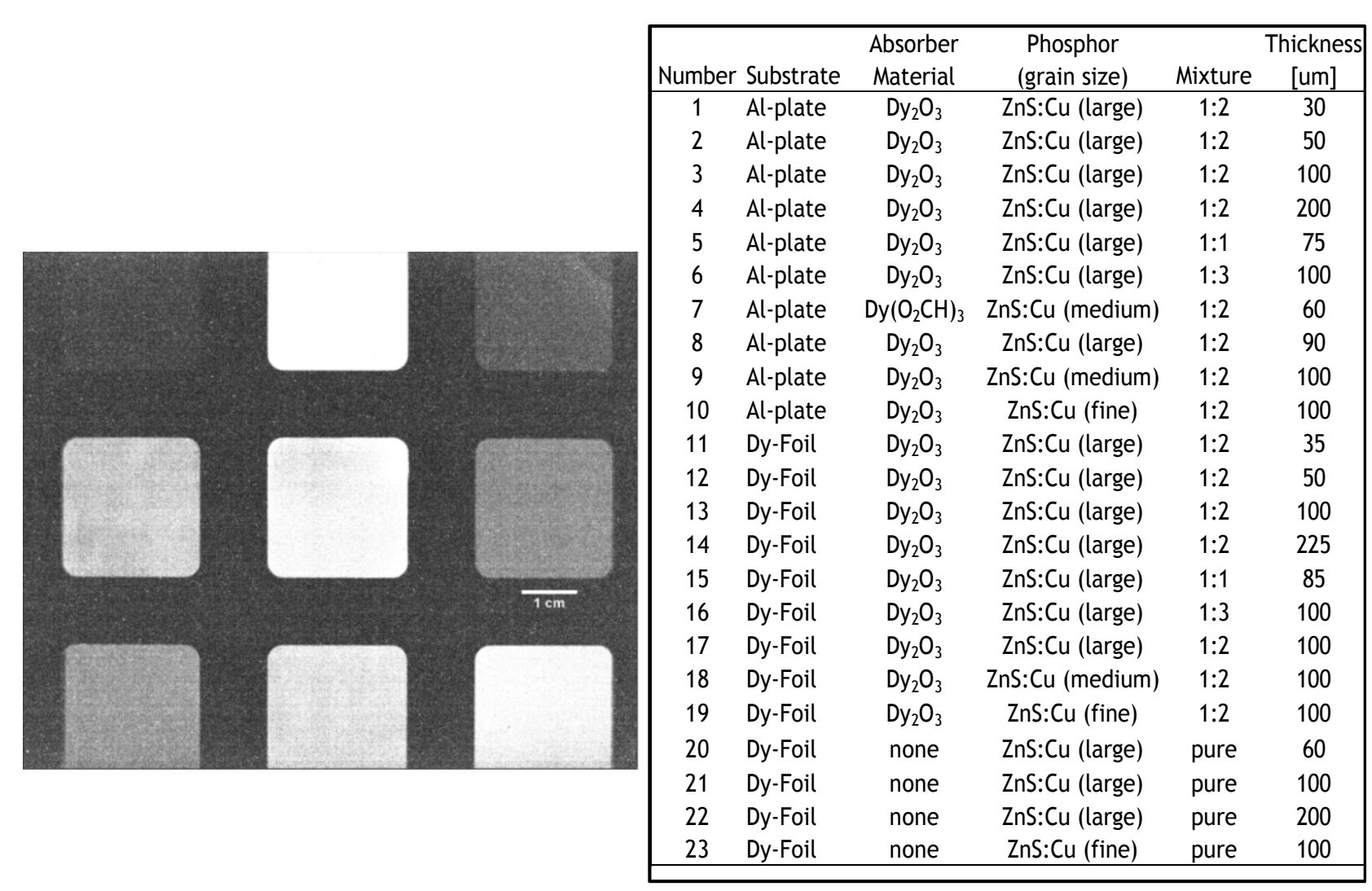

(Left) Neutron radiograph of scintillator screens. (Right). Table of Dy scintillator screens tested at PSI. 


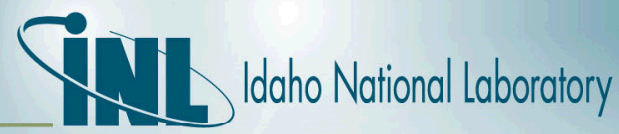

\section{Further Screen Testing at FRM II}

- Top performers from first tests AND new screens tested at the ANTARES cold neutron beam at Technical University Munich's FRM II reactor.

- Neutron flux: $1 \times 10^{8} \frac{n}{\mathrm{~cm}^{2} \mathrm{~s}}$ at $L / D=400$.

(Top) Neutron radiograph demonstrating scintillator screen positioning. (Bottom left) Table of tested scintillator screens. (Bottom right) Spatial resolution results from testing.

\begin{tabular}{|c|c|c|c|c||c|c|}
\hline $\begin{array}{c}\text { Scintillator } \\
\text { ID }\end{array}$ & Phosphor & Substrate & Converter & Ratio & $\begin{array}{c}\text { Thickness } \\
(\mu \mathrm{m})\end{array}$ & $\begin{array}{c}\text { Size } \\
(\mathrm{cm} \times \mathrm{cm})\end{array}$ \\
\hline $1-3$ & ZnS:Cu (large grains) & Al Plate & $\mathrm{Dy}_{2} \mathrm{O}_{3}$ & $1: 2$ & 100 & $\sim 2.54 \times \sim 2.54$ \\
\hline $1-4$ & ZnS:Cu (large grains) & Al Plate & $\mathrm{Dy}_{2} \mathrm{O}_{3}$ & $1: 2$ & 200 & $\sim 2.54 \times \sim 2.54$ \\
\hline $1-13$ & ZnS:Cu (large grains) & Dy-Foil & $\mathrm{Dy}_{2} \mathrm{O}_{3}$ & $1: 2$ & 100 & $\sim 2.54 \times \sim 2.54$ \\
\hline $1-14$ & ZnS:Cu (large grains) & Dy-Foil & $\mathrm{Dy}_{2} \mathrm{O}_{3}$ & $1: 2$ & 225 & $\sim 2.54 \times \sim 2.54$ \\
\hline $1-20$ & ZnS:Cu (large grains) & Dy-Foil & None & Pure & 60 & $\sim 2.54 \times \sim 2.54$ \\
\hline $1-21$ & ZnS:Cu (large grains) & Dy-Foil & None & Pure & 100 & $\sim 2.54 \times \sim 2.54$ \\
\hline \hline $1-22$ & ZnS:Cu (large grains) & Dy-Foil & None & Pure & 200 & $\sim 2.54 \times \sim 2.54$ \\
\hline $2-1$ & ZnS:Cu, Al & Dysprosium & None & Pure & 100 & $5.7 \times 5.7$ \\
\hline $2-2$ & ZnS:Cu, Al & Dysprosium & None & Pure & 200 & $5.7 \times 5.7$ \\
\hline $2-3$ & ZnS:Cu, Al & Dysprosium & None & Pure & 300 & $5.7 \times 5.7$ \\
\hline $2-4$ & ZnS:Ag & Dysprosium & None & Pure & 100 & $5.7 \times 5.7$ \\
\hline $2-5$ & ZnS:Ag & Dysprosium & None & Pure & 200 & $5.7 \times 5.7$ \\
\hline $2-6$ & ZnS:Ag & Dysprosium & None & Pure & 300 & $5.7 \times 5.7$ \\
\hline $2-7$ & GOS:Tb & Dysprosium & None & Pure & 100 & $5.7 \times 5.7$ \\
\hline $2-8$ & GOS:Tb & Dysprosium & None & Pure & 200 & $5.7 \times 5.7$ \\
\hline $2-9$ & GOS:Tb & Dysprosium & None & Pure & 300 & $5.7 \times 5.7$ \\
\hline
\end{tabular}

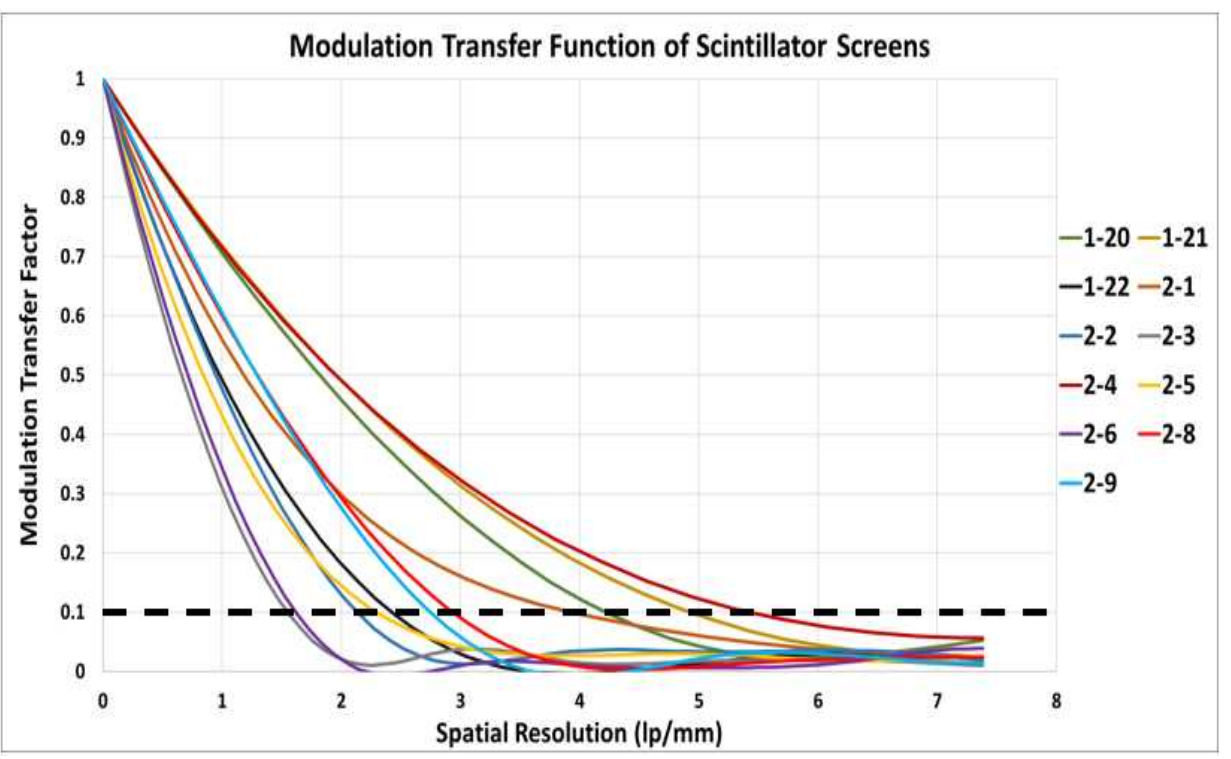




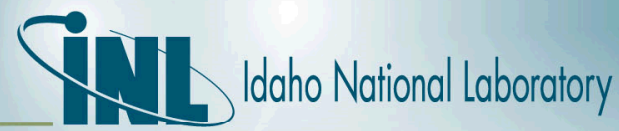

\section{Imaging Fuel at INL: Experimental Set-Up}

- Andor Ikon-M CCD camera used to acquire data.

- Air cooling used to suppress thermal noise.

- Linear stage remotely positions and focuses the camera.

- Light tight box to reduce ambient light.

- Telemetry placed on cassette to measure the dose rate from fuel.

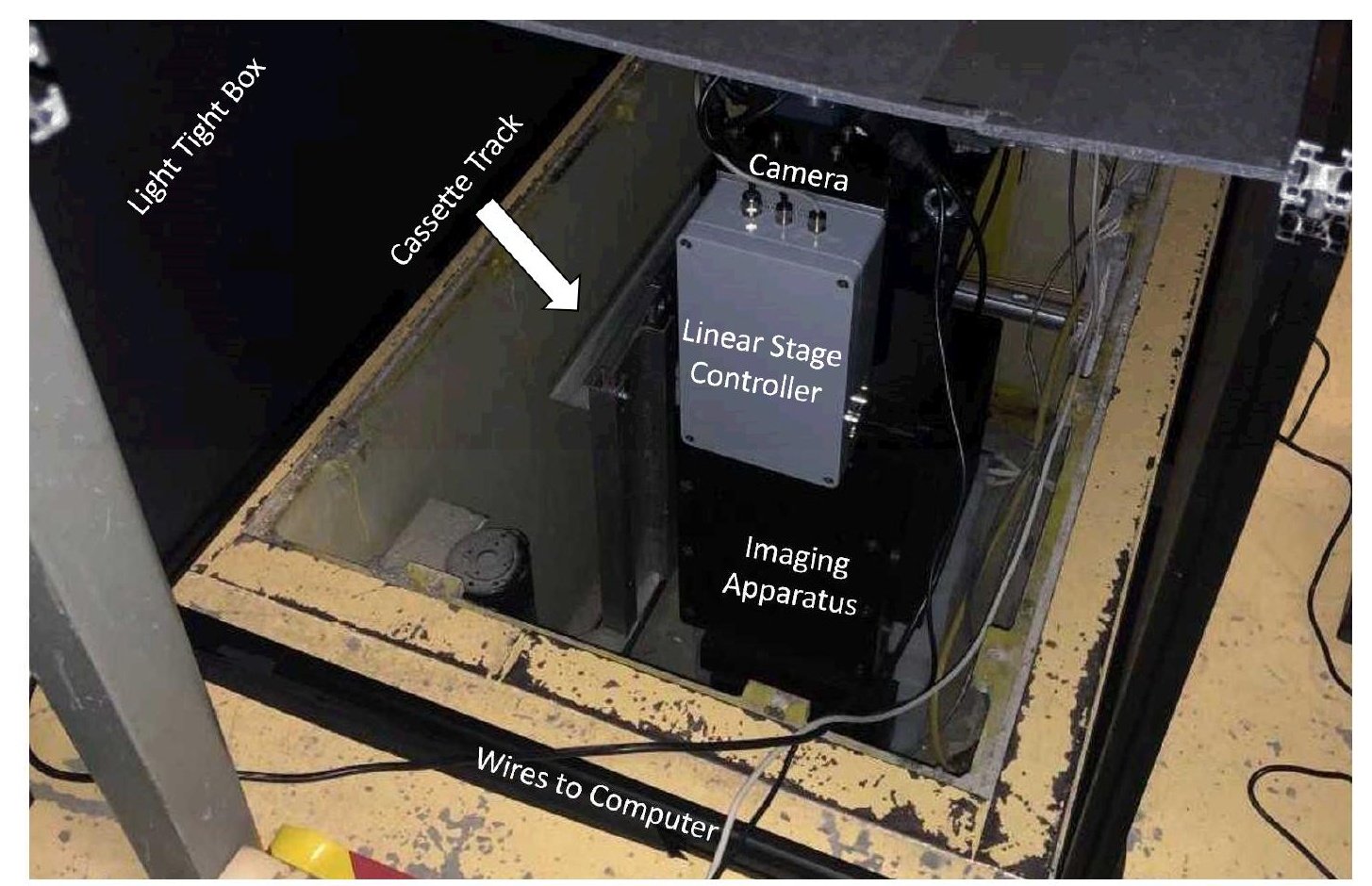

Picture of indirect digital neutron radiography system (with side panel removed). 


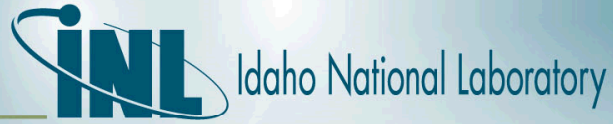

\section{Imaging Irradiated Nuclear Fuel at INL}

- Top performing screens used to image irradiated nuclear fuel.

- Various levels of performance observed across screens.

- EBR-II fuel pins imaged.

- Estimated dose rate: $\mathbf{5 0 0} \mathbf{R} / \mathbf{h r}$.

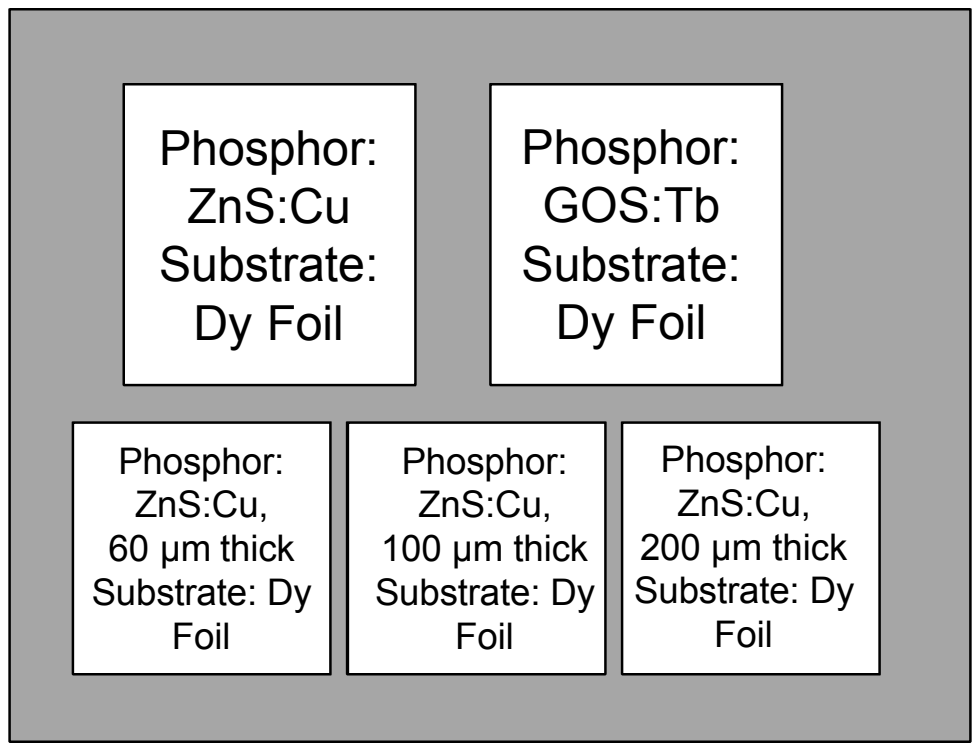

Schematic diagram of screen layout.

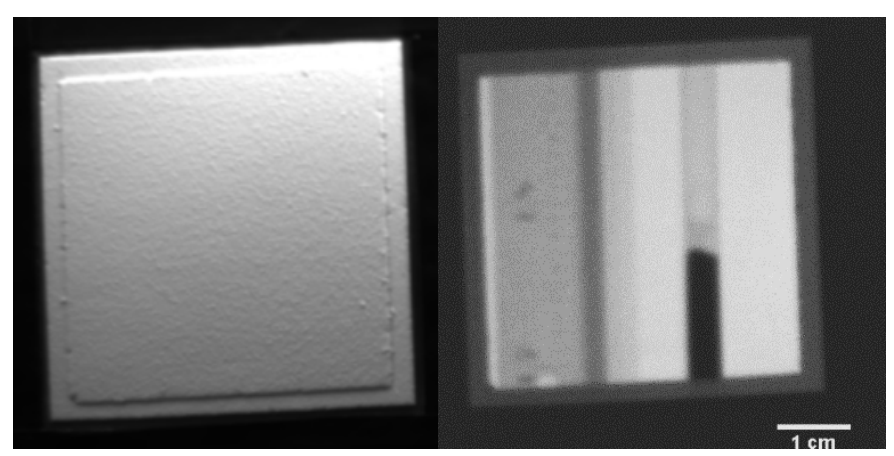

Optical image of scintillator screen (left) and radiograph of fuel (right).

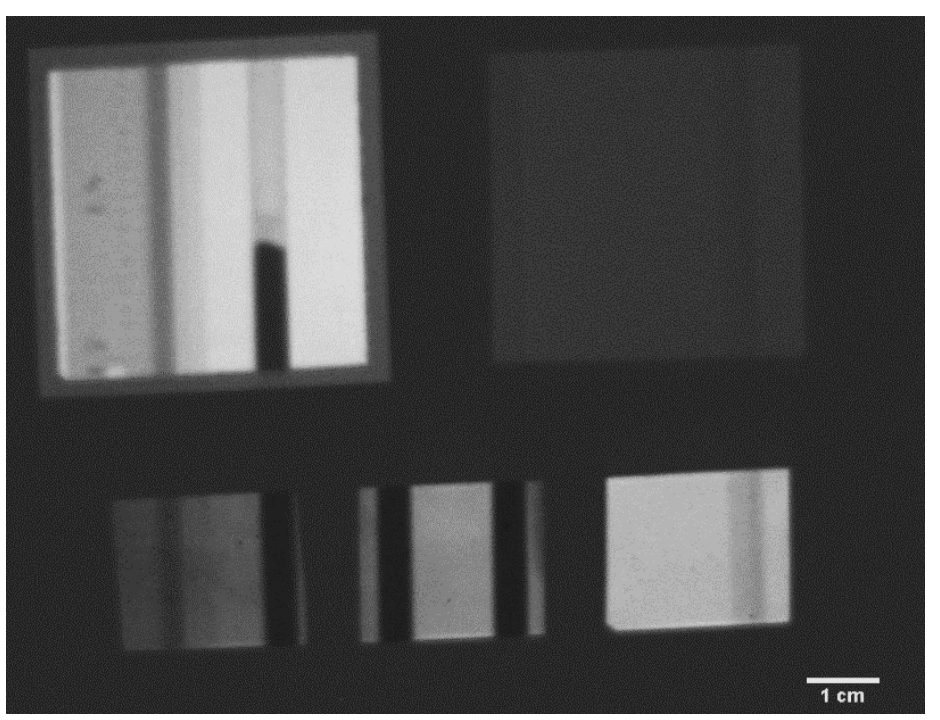

Radiographs of irradiated nuclear fuel. 


\section{ATF Fuel Images}

- Accident Tolerant Fuel (ATF) also imaged.

- Measured Dose Rate: 884 R/hr.

- Fuel rods are spaced with steel balls, which can be seen at the top of the image.
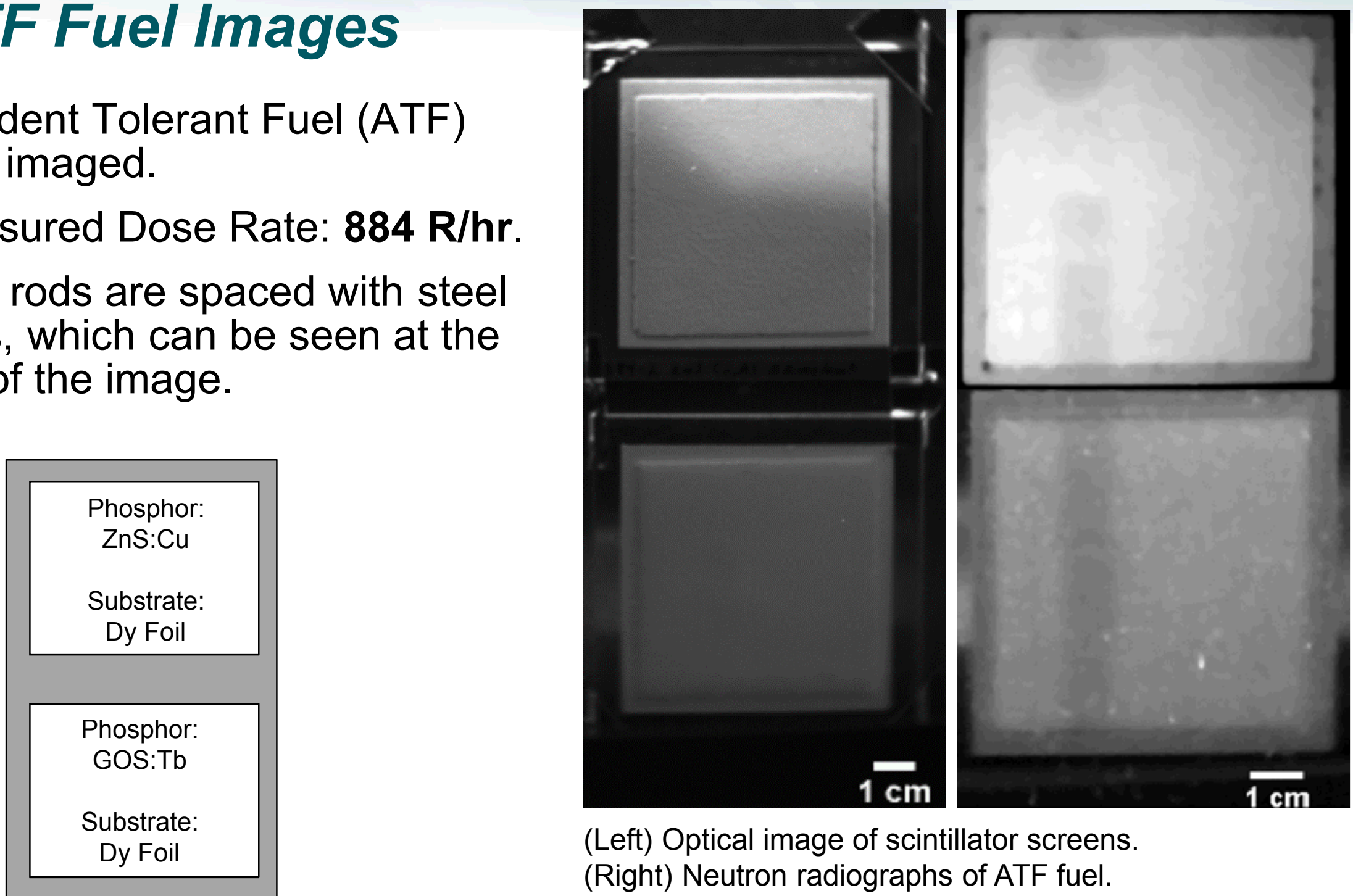

(Left) Optical image of scintillator screens.

(Right) Neutron radiographs of ATF fuel.

Screens are shown in different grayscale levels to provide

Schematic diagram of scintillator screen layout. best contrast for a visual image in each. 


\section{Conclusions}

- Neutron radiography is a nondestructive evaluation tool that can be used to examine nuclear fuels.

- Direct and indirect neutron radiography have advantages \& disadvantages.

- This is the first time this novel approach combining both methods was used to digitally examine irradiated nuclear fuels.
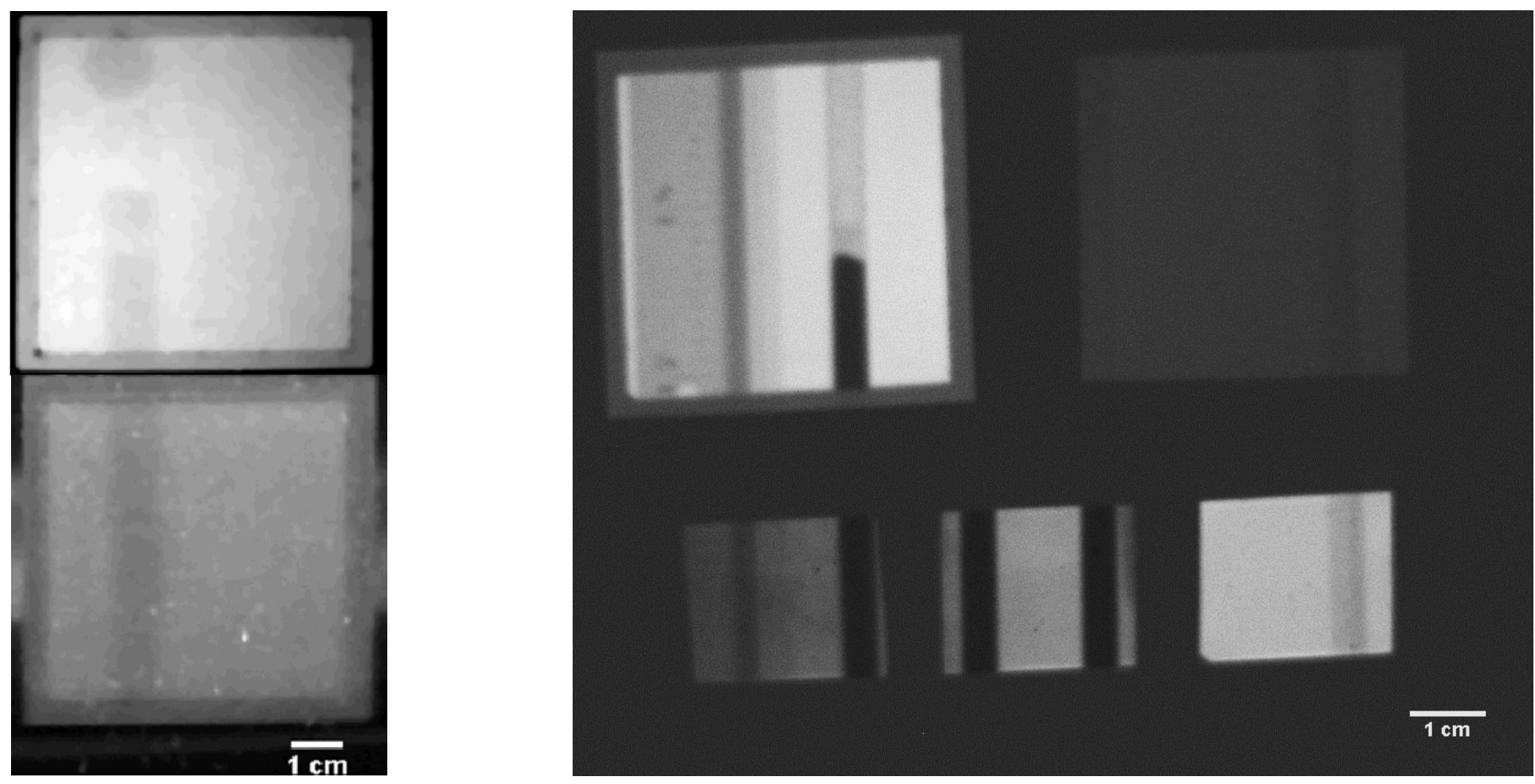
